\title{
Quality of life of asthmatic adolescents: assessment of asthma severity, comorbidity, and life style
}

\author{
Katia T. Nogueira, ${ }^{1}$ José Roberto L. Silva, ${ }^{2}$ Claudia S. Lopes ${ }^{3}$
}

\begin{abstract}
Objective: To assess the quality of life (QoL) of asthmatic adolescents and its association with asthma severity, chronic diseases, and life style.

Method: Cross-sectional study involving 210 female and male asthmatic adolescents between 12 and 21 years old. The Paediatric Asthma Quality of Life Questionnaire, a self-administered instrument, was used. Explanatory variables were: allergic diseases, use of medication, passive smoking, occupational status, asthma severity, and life style. The analyses considered the dichotomous outcome (good/poor QoL) based on the mean scores. Generalized linear models (log-binomial) were used to calculate the crude and adjusted prevalence ratios (PR).

Results: Forty-six per cent of the girls and $57 \%$ of the boys had poor QoL. There was no correlation between chronic diseases and poor QoL. Low educational level, use of medication, passive smoking, and occupational factors had a statistically significant association $(p<0.05)$ with poor QoL. The adjusted analysis showed that severe asthma $(P R=1.53 ; 95 \% C I 1.12-2.11)$, use of medication ( $P R=1.58 ; 95 \% C I 1.09-2.28)$, having asthma diagnosis established less than 5 years ago $(P R=1.30 ; 95 \% C I 0.97-1.86)$, passive smoking $(P R=1.38 ; 95 \% C I 1.35-2.00)$, and being employed ( $P R=1.30 ; 95 \%$ CI 0.96-1.74) were associated with poor QoL.

Conclusion: A multidisciplinary team needs to face the challenge of providing good QoL with the purpose of making these patients better adapted to society and to their own needs.
\end{abstract}

J Pediatr (Rio J). 2009;85(6):523-530: Quality of life, asthma, adolescents, chronic disease.

\section{Introduction}

Asthma is a public health problem and one of the main reasons for emergency department visits in hospitals in Brazil and all around the world. In many cases, the frequent medical visits for asthma demonstrate an inappropriate control of the disease. ${ }^{1}$ The direct costs with asthma treatment are calculated based on the sum of expenses with medication, devices, medical visits, and hospitalizations. The indirect costs involve school and work absence, both related to patients and their caregivers, in addition to loss of productivity, early retirement, and death. ${ }^{2}$
Asthma affects a significant portion of the population, mainly children and adolescents, with high social and economic costs. The multicentric study International Study for Asthma and Allergies in Childhood (ISAAC), ${ }^{3}$ conducted in 56 countries, showed a variability in the prevalence of active asthma from 1.6 to $36.8 \%$, and Brazil was ranked 8 th with a mean prevalence of $20 \%$. Studying the Brazilian adolescent population in the ISAAC - Phase 3, Solé et al. ${ }^{4}$ found a mean prevalence of $19 \%$ of active asthma symptoms.

1. Doutora, Epidemiologia. Médica, Núcleo de Estudos da Saúde do Adolescente, Universidade do Estado do Rio de Janeiro (UERJ), Rio de Janeiro, RJ, Brazil.

2. Professor titular, Pneumologia, Faculdade de Medicina, Universidade Federal do Rio de Janeiro (UFRJ), Rio de Janeiro, RJ, Brazil.

3. Professor adjunto, Departamento de Epidemiologia, Instituto de Medicina Social, UERJ, Rio de Janeiro, RJ, Brazil.

This study was conducted at the Center of Studies on Adolescent Health (NESA), Universidade do Estado do Rio de Janeiro (UERJ), Rio de Janeiro, RJ, Brazil. No conflicts of interest declared concerning the publication of this article.

Suggested citation: Nogueira KT, Silva JR, Lopes CS. Quality of life of asthmatic adolescents: assessment of asthma severity, comorbidity, and life style. J Pediatr (Rio J). 2009;85(6):523-530.

Manuscript submitted Mar 23 2009, accepted for publication Oct 212009

doi:10.2223/JPED.1957 
Adolescence is the period of transition between childhood and adulthood and it is characterized by spurts of physical, mental, emotional, sexual, and social development and by efforts carried out by the individual in order to reach the goals related to the cultural expectations of the society where he lives. Asthma is one of the main diseases of childhood and adolescence, being the main chronic respiratory disease in adolescents, and its consequences affect not only the patient but also the whole family, with the possibility of causing complex problems and having long-term implications. ${ }^{5}$ In addition to the problems inherent to adolescence, the association of a chronic disease with asthma may produce feelings of failure, lack of hope, anger, and self-censorship, lack of self-esteem, and fear represent an extra burden for these adolescents. Sawyer et al., ${ }^{6}$ in a cohort study, found a decrease in the quality of life (QoL) in adolescents with chronic diseases such as asthma and diabetes.

QoL in patients with chronic diseases, mainly asthma, is increasingly being the focus of research.

The World Health Organization-Quality of Life Group $\left(\right.$ WHOQOL) ${ }^{7}$ established that QoL is the "individuals' perception of their position in life in the context of the culture and value systems in which they live and in relation to their goals, expectations, standards and concerns." It is a broad concept influenced in a complex manner by physical health, psychological state, independence level, social relations, and relations with the characteristics of the environment where the individuals live.

The measures of assessment of asthma morbidity, such as symptoms, physiological measures, medications, and use of health care services demonstrate only part of the morbidity picture of asthma, since they do not inform how patients feel in their daily living. QoL questionnaires may be useful for that purpose and they also make it possible to validate other measures of asthma morbidity. ${ }^{8}$

Recent studies have shown that patients with asthma have low self-reported QoL. ${ }^{9}$ Even if the QoL is worse in the patients with severe asthma, the number of reports of poor QoL in patients with moderate asthma is significant.10 At any level of asthma severity, there is reduction in the physical, psychological, and social domains, since most asthmatics have to face restrictions in their lives and have a worse health status than nonasthmatic individuals. ${ }^{11-13}$

This is a pioneering study in the Brazilian literature and its objective is to investigate the association between the severity of asthma diagnosis, time of diagnosis, comorbidity, life style, and QoL in asthmatic adolescents.

\section{Methods, study design, and population}

This is a cross-sectional outpatient study. Two hundred and forty asthmatic adolescents met the inclusion criteria of the study, which accounts for $35 \%$ of the 688 patients who received regular care at the outpatient clinic of Allergy and Immunology of the adolescent service (12 to 21 years) of a teaching hospital in the state of Rio de Janeiro, Brazil. The period of study was from March to November 2006, and all patients were eligible for the study. Once a week, the adolescents were recruited at the outpatient clinic of Allergy and Immunology (Program of Quality of Life in Respiratory Diseases). Only one family refused to participate in the study, and 29 questionnaires were not fully and adequately completed or did not meet the criteria for asthma classification. Two hundred and ten adolescents were assessed.

The diagnosis of asthma established using the clinical evaluation recommended by the 3rd Brazilian Asthma Consensus and the respiratory function test were the eligibility criteria. The assessment of the disease was carried out using the following classification levels: mild, moderate, and severe. ${ }^{14}$ Time of diagnosis, age at diagnosis, and presence of other associated allergic diseases were analyzed, and the respiratory function test was carried out. The clinical assessment was conducted by means of physical examination, during which weight, height, body mass index (BMI), and Tanner index were measured. All tests were performed by the researcher at the allergy outpatient clinic. The respiratory function test was carried out at the Pulmonology Department of the teaching hospital.

Initially, socioeconomic and demographic data were collected, including age, sex, parents' educational level, adolescents' educational level, adolescents' occupational status, adolescents and parents' marital status, race, and family income. We also assessed the following factors: presence of pets, family history of allergy, use of alternative treatments, smoking, physical activity, use of medication, and presence of other chronic diseases.

With the purpose of assessing the QoL, we used the Paediatric Asthma Quality of Life Questionnaire (PAQLQ), which was designed by Juniper et al. ${ }^{15}$ to be specifically used in clinical trials aimed at assessing and following-up asthma, being initially validated and published in English. The PAQLQ was validated and adapted to other languages and in other countries including Brazil. ${ }^{16}$ Several other questionnaires were developed to assess the QoL of children and adolescents with asthma.15,16

This instrument has 23 items and three domains (symptoms, activity limitation, and emotional function) and it is able to quantify changes in the QoL of individuals throughout time. Its validation for Brazilian Portuguese was carried out by La Scala et al., ${ }^{17}$ and the questionnaire was designed to be administered to children between 7 and 17 years old by means of face-to-face interviews or to be completed by the subjects during an average period of 10 minutes. The answer options for each item were 
classified according to a scale of 7 points, where 1 means the highest impairment and 7 means no impairment. Results are expressed as mean of total scores. QoL was treated as a dichotomous variable (good/poor) using the mean scores.

The sociodemographic and economic variables included in the questionnaire were: sex, race (white, black, brown), age (younger than 15 years old and older than or 15 years old), parents' educational level, adolescents' educational level (incomplete elementary school, elementary school, incomplete high school, high school, and university), adolescents and parents' marital status, family income (up to one minimum salary, from one to two minimum salaries, from two to four minimum salaries, and more than five salaries), if the adolescents live with their parents or with other people, and the number of people living in the house. The explanatory variables were asthma classification (mild, moderate, severe), time of diagnosis (less than 5 years ago and more than 5 years ago), presence of other chronic and/or allergic diseases (rhinitis, allergic conjunctivitis, atopic dermatitis, contact dermatitis, urticaria), passive and active smoking, use of alternative treatments, occupational status, practice of physical activity, and presence of pets.

\section{Data analysis}

The computer program Epi-Info 2000 was used to enter the data. First, we calculated and analyzed the distributions of frequency and the graphs of each variable. Next, when the QoL was treated as a dichotomous variable, bivariate and multivariate analyses between exposure and outcome variables were assessed using prevalence ratios (PR). In the bivariate analysis, the chi-square test (independence) and Fisher's exact test were used to assess the statistical significant between the associations, and a $5 \%$ significance level was set.

In the multivariate analysis, although the traditional logistic regression model is often used in prevalence studies, in the present study, we decided to use the log-binomial regression model, 17,18 since this model is able to directly estimate PR. The logistic regression model estimates the odds ratio (OR), overestimating the PR when the outcome prevalence is quite high in the population of the study, as it was the case in the present study. The log-binomial model was adjusted, containing all exposure variables. We set the significance level at 0.10 to select the variables that would be included in the final model to avoid excluding the potential confounding factor, and the $5 \%$ significance level was used to indicate a statistically significant association. After selecting the variables that had a statistically significant association with the outcome, we adjusted the final model with higher statistical power of the outcome.
All statistical analyses were carried out using the statistical package $R$, version 2.3.4. ${ }^{19}$

\section{Ethical aspects}

Before data collection, the protocols related to the study were approved by the Research Ethics Committee of Hospital Universitário Pedro Ernesto, Rio de Janeiro, state of Rio de Janeiro, Brazil, since the Center of Studies on Adolescent Health (NESA) is subordinated to the hospital. The study was considered adequate for a human sample. Participation was volunteer-based, and the adolescents and their families were informed that no penalty would be applied to those who did not wish to participate. After receiving information about the study, the participants or their guardians were asked to read the consent form, a document provided and signed by the guardians of the adolescents younger than 18 years old and by the adolescents older than 18 years old who were interviewed. This document included information on the relevance of the study; therefore, adolescents and their guardians were informed on the importance of their participation.

\section{Results}

Of the 210 patients, $39 \%$ were male and $54 \%$ were older than 15 years. In terms of race, $47 \%$ were white, $19 \%$ were black, and 34\% were brown. Most of the sample was single (90\%). Approximately $44.7 \%$ of the sample belonged to the third stratum of family income (from two to four minimum salaries), half of the population had an educational level equal to or higher than incomplete high school (51.5\%), and there was adequacy between educational level and age (Table 1).

Half of the asthmatic adolescents of both sexes were considered to have poor QoL. Among the boys, 57\% had poor QoL, whereas among the girls, this percentage was $46 \%$, but this difference was not statistically significant (Table 1).

Adolescents who had not completed elementary school (59.65\%) had worse QoL, and this association was statistically significant. No other sociodemographic variable showed a statistically significant association with QoL in this population.

The prevalence rates of risk factors related to the QoL are described in Table 2. Practice of physical activity did not have an influence on the QoL. We found worse QoL in the adolescents who use medication, those who are passive smokers, and in the patients with severe asthma (57.76\%). Having a BMI higher than 25 and the presence of pets at home showed a borderline association with QoL.

Presence of atopic dermatitis showed a borderline association with the QoL. There was no relation between 
having other allergic disease or a non-allergic chronic disease and the QoL (Table 3).

The final model adjusted according to sex, age, and educational level (Table 4) showed a marginally significant association between worse QoL and severe asthma, use of medication, being a passive smoker, and being employed. Having a diagnosis of asthma for a period shorter than
5 years also demonstrated QoL impairment $[\mathrm{PR}=1.30$; $95 \%$ confidence interval (95\%CI) 0.96-1.86].

\section{Discussion}

The QoL of patients with chronic diseases, mainly asthma, is increasingly being the focus of research. Our study showed

Table 1 - Sociodemographic factors and quality of life of asthmatic adolescents seen at an outpatient clinic of a teaching hospital $(n=210)$

\begin{tabular}{|c|c|c|c|c|}
\hline \multirow[b]{2}{*}{ Characteristics } & \multirow[b]{2}{*}{ Total, n (\%) } & \multicolumn{2}{|c|}{ Quality of life } & \multirow[b]{2}{*}{$\mathbf{p}$} \\
\hline & & Good, n (\%) & Poor, n (\%) & \\
\hline \multicolumn{5}{|l|}{ Sex } \\
\hline Female & $128(60.95)$ & $69(53.91)$ & $59(46.09)$ & \\
\hline Male & $82(39.05)$ & $35(42.68)$ & $47(57.32)$ & 0.628 \\
\hline \multicolumn{5}{|l|}{ Race } \\
\hline Black & $40(19.05)$ & $19(47.50)$ & $21(52.50)$ & \\
\hline White & $98(46.67)$ & $56(57.14)$ & $42(42.86)$ & \\
\hline Brown & $72(34.28)$ & $41(56.94)$ & $31(43.06)$ & 0.556 \\
\hline \multicolumn{5}{|l|}{ Age } \\
\hline$<15$ years old & $75(35.71)$ & $35(46.60)$ & $40(54.40)$ & \\
\hline$\geq 15$ years old & $135(64.29)$ & $81(60.00)$ & $54(40.00)$ & 0.405 \\
\hline \multicolumn{5}{|l|}{ Educational level } \\
\hline Incomplete elementary school & $57(27.40)$ & $23(40.35)$ & $34(59.65)$ & \\
\hline Elementary school & $44(21.15)$ & $23(52.27)$ & $21(47.73)$ & \\
\hline Incomplete high school & $66(31.73)$ & $48(72.73)$ & $18(27.27)$ & \\
\hline High school & $41(19.71)$ & $22(53.66)$ & $19(46.34)$ & 0.001 \\
\hline \multicolumn{5}{|l|}{ Father's educational level } \\
\hline Incomplete elementary school & $65(32.83)$ & $34(52.31)$ & $31(47.69)$ & \\
\hline Elementary school & $52(26.26)$ & $25(48.08)$ & $27(51.92)$ & \\
\hline Incomplete high school & $22(11.11)$ & $12(54.55)$ & $10(45.45)$ & \\
\hline High school & $59(29.80)$ & $39(66.10)$ & $20(33.90)$ & 0.141 \\
\hline \multicolumn{5}{|l|}{ Mother's educational level } \\
\hline Incomplete elementary school & $68(32.54)$ & $38(55.88)$ & $30(44.12)$ & \\
\hline Elementary school & $56(26.79)$ & $27(48.21)$ & $29(51.79)$ & \\
\hline Incomplete high school & $24(11.48)$ & $11(45.83)$ & $13(54.17)$ & \\
\hline High school & $61(29.19)$ & $40(65.57)$ & $21(34.43)$ & 0.328 \\
\hline \multicolumn{5}{|l|}{ Married } \\
\hline Yes & $20(9.57)$ & $11(55.00)$ & $9(45.00)$ & \\
\hline No & $189(90.43)$ & $105(55.56)$ & $84(44.44)$ & 0.962 \\
\hline \multicolumn{5}{|l|}{ Family income } \\
\hline Up to $1 \mathrm{MS}$ & $13(6.19)$ & $6(46.15)$ & $7(53.85)$ & \\
\hline From 1 to $2 \mathrm{MS}$ & $72(34.29)$ & $40(55.56)$ & $32(44.44)$ & \\
\hline From 2 to $4 \mathrm{MS}$ & $94(44.76)$ & $54(57.45)$ & $40(42.55)$ & \\
\hline$\geq 4 \mathrm{MS}$ & $31(14.76)$ & $16(51.61)$ & $15(48.39)$ & 0.545 \\
\hline \multicolumn{5}{|l|}{ Parents' marital status } \\
\hline Single & $3(1.44)$ & $3(100.00)$ & $0(0.00)$ & \\
\hline Married & $134(64.11)$ & $72(53.73)$ & $62(46.27)$ & \\
\hline Separated & $57(27.27)$ & $32(56.14)$ & $25(43.86)$ & \\
\hline Widow/Widower & $15(7.18)$ & $9(60.00)$ & $6(40.00)$ & 0.439 \\
\hline \multicolumn{5}{|l|}{ Housing } \\
\hline Living with parents & $165(83.33)$ & $96(58.18)$ & $69(41.82)$ & \\
\hline Living with other people & $33(16.67)$ & $15(45.45)$ & $18(54.55)$ & 0.059 \\
\hline \multicolumn{5}{|l|}{ No. of people living in the house } \\
\hline$\leq 3$ & $51(24.88)$ & $30(58.82)$ & $21(41.18)$ & \\
\hline 4 or 5 & $118(57.56)$ & $67(56.78)$ & $51(43.22)$ & \\
\hline$>5$ & $36(17.56)$ & $18(50.00)$ & $18(50.00)$ & 0.693 \\
\hline
\end{tabular}

$\mathrm{MS}=$ minimum salary 
a decrease in the QoL in all levels of asthma severity (mild, moderate, and severe), and there was a worse association between severe asthma and QoL, which is in agreement with the international literature. Juniper ${ }^{11}$ conducted a large population-based study and found that asthmatics have a significantly worse QoL than those individuals who never suffered from asthma. We considered the findings and conclusions of author of the questionnaire to justify the statistical power of our prevalence ratios even though some of them were marginally significant.

We found that adolescents who used medication had worse QoL (PR $=1.58 ; 95 \%$ CI 1.09-2.28) when compared to those who did not take any medications; such association was expected, since the most severe patients are likely to have more acute exacerbations and often use corticosteroids or bronchodilators. The fact that these patients use these medications in a continuous and prophylactic manner suggests that there is an association with worse QoL. Poor QoL was also associated with passive smoking. Smoking adolescents are more prone to respiratory infections, asthma, oral pathologies, and reduced physical capacity. Passive smokers who live with smokers have a three-fold higher incidence of respiratory infections, as well as increased incidence of atopic diseases. ${ }^{20}$

Most of our population was comprised of girls (61\%), what may partially be explained by the fact that, among adolescents, asthma is significantly higher in this gender due to remission among boys and a larger number of new cases among girls. Another possible explanation is the fact that female individuals seek health care more often than the male population. Some recent studies have suggested that hormonal factors can be involved in this increase in the

Table 2 - Prevalence of risk factors and quality of life of asthmatic adolescents seen at an outpatient clinic of a teaching hospital $(n=210)$

\begin{tabular}{|c|c|c|c|c|}
\hline \multirow[b]{2}{*}{ Characteristics } & \multirow[b]{2}{*}{ Total, n (\%) } & \multicolumn{2}{|c|}{ Quality of life } & \multirow[b]{2}{*}{$\mathbf{p}$} \\
\hline & & Good, n (\%) & Poor, n (\%) & \\
\hline \multicolumn{5}{|l|}{ Asthma severity } \\
\hline Mild & 107 (50.95) & $68(63.55)$ & 39 (36.45) & \\
\hline Moderate & $66(31.43)$ & $32(48.48)$ & $34(51.52)$ & \\
\hline Severe & $37(17.62)$ & $16(43.24)$ & $21(57.76)$ & 0.042 \\
\hline \multicolumn{5}{|l|}{ Use of medication } \\
\hline Yes & $134(63.81)$ & $64(47.76)$ & $70(52.24)$ & \\
\hline No & $76(36.19)$ & $52(68.42)$ & $24(31.58)$ & 0.004 \\
\hline \multicolumn{5}{|l|}{ Smoker } \\
\hline Yes & $17(8.17)$ & $8(47.06)$ & $9(52.94)$ & \\
\hline No & $191(91.83)$ & $106(55.50)$ & $85(44.50)$ & 0.503 \\
\hline \multicolumn{5}{|l|}{ Passive smoker } \\
\hline Yes & $95(46.34)$ & $44(46.32)$ & $51(53.68)$ & \\
\hline No & $110(53.66)$ & $70(63.64)$ & $40(36.36)$ & 0.013 \\
\hline \multicolumn{5}{|c|}{ Practice of physical activity } \\
\hline Yes & $138(65.71)$ & $73(52.90)$ & $65(47.10)$ & \\
\hline No & $72(34.29)$ & $43(59.72)$ & $29(40.28)$ & 0.345 \\
\hline \multicolumn{5}{|c|}{ Alternative treatment } \\
\hline Yes & $48(23.30)$ & $27(56.25)$ & $21(43.75)$ & \\
\hline No & $158(76.70)$ & $87(55.06)$ & $71(44.94)$ & 0.885 \\
\hline \multicolumn{5}{|l|}{ Pets } \\
\hline Yes & 139 (66.19) & $70(50.36)$ & $69(49.64)$ & \\
\hline No & $71(33.81)$ & $46(64.79)$ & $25(35.21)$ & 0.047 \\
\hline \multicolumn{5}{|c|}{ Occupational status } \\
\hline Employed & $36(17.14)$ & $16(44.44)$ & $20(55.66)$ & \\
\hline Unemployed & $174(82.86)$ & $100(57.47)$ & $74(42.53)$ & 0.050 \\
\hline \multicolumn{5}{|l|}{ Body mass index } \\
\hline$\leq 25$ & $160(82.86)$ & $83(51.85)$ & $77(48.15)$ & \\
\hline$>25$ & $50(17.14)$ & $33(66.00)$ & $17(34.00)$ & 0.008 \\
\hline \multicolumn{5}{|l|}{ Time of diagnosis } \\
\hline$\leq 5$ years & $94(44.76)$ & $42(44.68)$ & $52(55.32)$ & \\
\hline$>5$ years & $116(55.24)$ & $64(55.17)$ & $50(44.83)$ & 0.006 \\
\hline
\end{tabular}


disease frequency in girls during adolescence. Our findings are also in agreement with cross-sectional and longitudinal studies conducted with this age group. ${ }^{21}$

With regard to the BMI, $17.14 \%$ of the patients were considered to be overweight. In the literature, overweight/ obesity is described as a risk factor for a higher incidence of asthma, mainly among females. ${ }^{22}$ In general, asthmatic adolescents are more often overweight than healthy controls. ${ }^{23,24}$ Kushinir $^{25}$ found a positive association between overweight adolescents aged 13 and 14 years and asthma symptoms $(\mathrm{OR}=1.51 ; 95 \% \mathrm{CI} 1.07-2.13)$. In our study, there was a borderline association.

Table 3 - Prevalence of other chronic diseases and quality of life of asthmatic adolescents at an outpatient clinic of a teaching hospital $(n=210)$

\begin{tabular}{|c|c|c|c|c|}
\hline \multirow[b]{2}{*}{ Characteristics } & \multirow[b]{2}{*}{ Total, n (\%) } & \multicolumn{2}{|c|}{ Quality of life } & \multirow[b]{2}{*}{$\mathbf{p}$} \\
\hline & & Good, n (\%) & Poor, n (\%) & \\
\hline \multicolumn{5}{|l|}{ Rhinitis } \\
\hline Yes & $182(87.08)$ & $103(56.59)$ & $79(43.41)$ & \\
\hline No & $27(12.92)$ & $13(48.15)$ & $14(51.85)$ & 0.410 \\
\hline \multicolumn{5}{|c|}{ Allergic conjunctivitis } \\
\hline Yes & $22(10.58)$ & $13(59.09)$ & $9(40.91)$ & \\
\hline No & $186(89.42)$ & $102(54.84)$ & $84(45.16)$ & 0.704 \\
\hline \multicolumn{5}{|l|}{ Atopic dermatitis } \\
\hline Yes & $10(4.81)$ & $3(30.00)$ & $7(70.00)$ & \\
\hline No & $198(95.19)$ & $112(56.57)$ & $86(43.43)$ & 0.099 \\
\hline \multicolumn{5}{|l|}{ Contact dermatitis } \\
\hline Yes & $18(8.57)$ & $13(72.22)$ & $5(27.78)$ & \\
\hline No & $191(91.43)$ & $103(53.93)$ & $88(46.07)$ & 0.135 \\
\hline \multicolumn{5}{|l|}{ Urticaria } \\
\hline Yes & $24(11.48)$ & $13(54.17)$ & $11(45.83)$ & \\
\hline No & $185(88.52)$ & $103(55.68)$ & $82(44.32)$ & 0.889 \\
\hline \multicolumn{5}{|l|}{ Chronic disease } \\
\hline Yes & $56(26.79)$ & $27(48.21)$ & $29(51.79)$ & \\
\hline No & $153(73.21)$ & $89(58.17)$ & $64(41.83)$ & 0.200 \\
\hline
\end{tabular}

Table 4 - Crude and adjusted prevalence ratios and respective $95 \%$ confidence intervals of the association between asthma severity, time of diagnosis, use of medication, being a passive smoker, and being employed and the quality of life of asthmatic adolescents at an outpatient clinic of a teaching hospital $(n=210)$

\begin{tabular}{|c|c|c|}
\hline Risk factors & Crude PR (95\%CI) & Adjusted PR (95\%CI)* \\
\hline \multicolumn{3}{|l|}{ Asthma severity } \\
\hline Mild & 1 & 1 \\
\hline Severe & $1.57(1.07-1.99)$ & $1.53(1.12-2.11)$ \\
\hline \multicolumn{3}{|c|}{ Use of medication } \\
\hline No & 1 & 1 \\
\hline Yes & $1.65(1.14-2.39)$ & $1.58(1.09-2.28)$ \\
\hline \multicolumn{3}{|l|}{ Passive smoker } \\
\hline No & 1 & 1 \\
\hline Yes & $1.47(1.08-2.01)$ & $1.38(1.35-2.00)$ \\
\hline \multicolumn{3}{|c|}{ Time of diagnosis } \\
\hline$>5$ years & 1 & 1 \\
\hline$\leq 5$ years & $1.38(1.02-1.86)$ & $1.30(0.96-1.86)$ \\
\hline \multicolumn{3}{|c|}{ Occupational status } \\
\hline Unemployed & 1 & 1 \\
\hline Employed & $1.39(0.93-1.83)$ & $1.30(0.97-1.74)$ \\
\hline
\end{tabular}

$95 \% \mathrm{Cl}=95 \%$ confidence interval; $\mathrm{PR}=$ prevalence ratio.

${ }^{*}$ All variables shown in this table were included in the adjusted models, as well as sex and age. 
Asthmatic female adolescents had better QoL when compared to male patients, which is in disagreement with the international literature that shows a higher impact of asthma on the female sex. Other studies that assessed QoL in women, such as Juniper et al. ${ }^{11}$ and Larson et al., ${ }^{26}$ also found that women had worse QoL.

In our study, the sociodemographic and economic characteristics were not associated with worse QoL in general. It is worth highlighting that $59.52 \%$ of the families have a monthly income higher than two minimum salaries, which within the Brazilian context is not considered to be unfavorable. Only the adolescents' educational level was associated with the QoL; however, there was not a consistent pattern.

It is common sense that allergy to cats is a risk factor for asthma during childhood and adolescence. Nevertheless, epidemiological studies about this association have provided findings that are difficult to interpret. In our study, there was a borderline association. However, some studies showed a protective effect of the exposure to dogs and cats on the development of asthma during childhood, but this was not the case for adolescents and adults; while other studies reported that the effects of the association with asthma may vary according to age of exposure, type of animal, and genetic predisposition. ${ }^{27}$

With regard to QoL and socioeconomic status, Leidy \& Coughlin ${ }^{28}$ described a direct and significant relation between high educational level and better QoL. Schimer et al. ${ }^{29}$ suggested that there is a close relation between health QoL and disease severity, sociodemographic factors, and treatment. For La Scala et al., ${ }^{17}$ asthma affects the QoL as a whole and has a deep impact on physical and functional health.

Regarding the risk factors, even though the concomitant presence of other chronic diseases has not shown statistical significance in the QoL in our study, there was a high prevalence of allergic rhinitis among our patients (87\%). According to the literature, allergic rhinitis is a public health problem and it affects from 10 to $25 \%$ of the world population; our findings reinforce the concept of "a single airway." ${ }^{30}$

The great limitation of the present study is related to its cross-sectional design, since all data were collected at the same moment.

It is also worth mentioning that the present study was conducted with a sample of adolescents who had peculiar characteristics, which restricts the possibility of extrapolating our findings to the general population. However, the findings of the present study are consistent with those of the international literature, what reinforces the need of longitudinal studies assessing the role played by asthma and QoL in the life of adolescents at the long term.
We concluded that this study evidences the association between worse QoL and asthma. Data interpretation suggests that there is need of investigating these relations in asthma morbidity with the purpose of supporting health care measures aimed at guaranteeing good QoL for adolescents with asthma. The results are of great interest for all those who work with adolescents with chronic diseases, mainly those with asthma, and will also help to understand and identify the comorbidity factors of asthmatic adolescents.

\section{References}

1. Castro RC, Santos NO, Morettom LT. Depressão e eventos de vida relacionados à asma grave. Rev Bras Alerg Imunopatol. $2001 ; 24: 204-11$

2. Oliveira MA, Muniz MT, Santos LA, Faresin SM, Fernandes AL. Custo-efetividade de programa de educação para adultos asmáticos atendidos em hospital-escola de instituição pública. J Pneumol. 2002;28:71-6.

3. Worldwide variations in the prevalence of asthma symptoms: the International Study of Asthma and Allergies in Childhood (ISAAC). Eur Respir J. 1998;12:315-35.

4. Solé D, Wandalsen G F, Camelo-Nunes IC, Naspitz CK, ISAAC - Study Group. Prevalence of symptoms of asthma, rhinitis and atopic eczema among Brazilian children and adolescents identified by the International Study of Asthma and Allergies (ISAAC) - Phase 3. J Pediatr (Rio J). 2006;82:341-6.

5. Camelo-Nunes I, Sole D. Pneumologia na adolescência. J Pediatr (Rio J). 2001;77:S143-52.

6. Sawyer MG, Reynolds KE, Couper JJ, French DJ, Kennedy D, Martin J, Staugas R, et al. Health-related quality of life of children and adolescents with chronic illness - a two year prospective study. Qual Life Res. 2004;13:1309-19.

7. World Health Organization Quality of life Instruments (WHOQOL). Measuring Quality of Life.2009. http://www.who.int/substance_ abuse/.../whoqolbref/en.

8. Jones PW, Quirk FH, Baveystock CM, Littlejohns P. A self-complete measure of health status for chronic airflow limitation. The St. George's Respiratory Questionnaire. Am Rev Respir Dis. 1992;145:1321-7.

9. Opolski M, Wilson I. Asthma and depression: a pragmatic review of the literature and recommendations for future research. Clin Pract Epidemol Ment Health. 2005;27:1-18.

10. Ford ES, Mannino DM, Homa DM, Gwynn C, Redd SC, Moriarty DG, et al. Self-reported asthma and health-related quality of life: findings from the behavioral risk factor surveillance system. Chest. 2003;123:119-27.

11. Juniper EF. Effect of asthma on quality of life. Can Respir J. 1998;5 Suppl A: 77A-84A.

12. Australian Centre for Asthma Monitoring (ACAM): Measuring the impact of asthma on quality of life in the Australian population. Canberra: Australian Institute of Health and Welfare; 2004.

13. Ramírez Narváez C, González Moro P, del Castillo Gómez L, García Cos JL, Lahoz Rallo B, Barros Rubio C. [Quality of life in a population of asthmatic children]. Aten Primaria. 2006;38:96-101.

14. III Consenso Brasileiro no Manejo da Asma (CBMA). J Pneumol. 2002;28(Supl 1).

15. Juniper EF, Svensson K, Mörk AC, Ståhl E. Modification of the asthma quality of life questionnaire (standardised) for patients 12 years and older. Health Qual Life Outcomes. 2005;3:58.

16. Rutishauser C, Sawyer SM, Bond L, Coffey C, Bowes G. Development and validation of the Adolescent Asthma Quality of Life Questionnaire (AAQOL). Eur Respir J. 2001;17:52-8. 
17. La Scala CS, Naspitz CK, Solé D. Adaptação e validação do Pediatric Asthma Quality of Life Questionnaire (PAQLQ-A) em crianças e adolescentes brasileiros com asma. J Pediatr (Rio J). 2005;81:54-60.

18. Skov T, Deddens J, Petersen MR, Endahl L. Prevalence proportion ratios: estimation and hypothesis testing. Int J Epidemiol. 1998;27:91-5.

19. R Development Core Team (2006). R: A language and environment for statistical computing. R Foundation for Statistical Computing, Vienna, Austria. ISBN 3-900051-07-0. http://www.R-project. org.

20. Taussig LM, Wright AL, Holberg CJ, Halonen M, Morgan WJ, Martinez FD. Tucson Children's Respiratory Study: 1980 to present. J Allergy Clin Immunol. 2003;111:661-75; quiz 676.

21. Fagan JK, Scheff PA, Hryhorczuk D, Ramakrishnan V, Ross M, Persky V. Prevalence of asthma and other allergic diseases in an adolescent population: association with gender and race. Ann Allergy Asthma Immunol. 2001;86:177-84.

22. Gilliland FD, Berhane K, Islam T, McConnell R, Gauderman WJ, Gilliland SS, et al. Obesity and the risk of newly diagnosed asthma in school-age children. Am J Epidemiol. 2003;158:406-15.

23. Castro-Rodríguez JA, Holberg CJ, Morgan WJ, Wright AL, Martinez FD. Increased incidence of asthmalike symptoms in girls who become overweight or obese during the school years. Am J Resp Crit Care Med. 2001;163:1344-9.

24. Cassol VE, Rizzato TM, Teche SP, Basso DF, Hirakata VN, Maldonado $M$, et al. Prevalência e gravidade da asma em adolescentes e sua relação com índice de massa corporal. J Pediatr (Rio J). 2005;81:305-9.
25. Kushinir FC. Prevalência, gravidade e fatores associados à asma em adolescentes do município de Nova Iguaçu [tese]. Rio de Janeiro: Universidade Federal do Rio de Janeiro; 2006.

26. Larson MG. Descriptive statistics and graphical displays. Circulation. 2006;114:76-81.

27. Lau S, Wahn U. Pets - good or bad for individuals with atopic predisposition? J Allergy Clin Immunol. 2003;112:263-4.

28. Leidy NK, Coughlin C. Psychometric performance of the Asthma Quality of Life Questionnaire in a US sample. Qual Life Res.1998;7:127-34.

29. Schmier JK, Chan KS, Leidy NK. The Impact of asthma on healthrelated quality of life. J Asthma. 1998;35:585-97.

30. BouSquet J, Van Cauwenberge P, Khaltaev N; Aria Workshop Group; World Health Organization. Allergic rhinitis and its impact on asthma. J Allergy Clin Immunol. 2001;108:S147-334.

Correspondence:

Katia T. Nogueira

Rua Benjamim Batista, 180/204 - Jardim Botânico

Rio de Janeiro, RJ - Brazil

Tel.: +55 (21) 2246.1120, +55 (21) 2266.4379

Fax: +55 (21) 2246.1120, +55 (21) 2266.4379

E-mail: katianog@terra.com.br 